\title{
Camping it up with EMI: The Politics of the Intersection of British Film Production with the Notion of Camp
}

\begin{abstract}
:
This article will explore two camp films released by EMI: the Danny La Rue star vehicle Our Miss Fred (1972) and the Village People 'biopic' Can't Stop the Music (1980), locating them within a broader tradition of British farcical humour and their respective cultural and industrial contexts. Through an examination of how these films operated as entertainment, the article argues that the intersection of EMI Films and camp actually helped to influence and modify cultural and social attitudes, particularly with regard to the gradual acceptance of the representation of queerness in 1970s and 1980s culture.
\end{abstract}

Keywords: EMI Films; camp; queer identity; British identity; 1970s culture; gay icons; Danny La Rue; the Village People.

\section{Introduction}

EMI Films emerged onto the British cinema scene in 1969 and endured until its demise in 1986. Its creation at such a volatile and radical moment in time, coinciding with the withdrawal of American financing from British film production, meant that the company would seek economic stability via a wide range of co-productions within not only a national, but also a transnational context. This had the unexpected consequence of EMI spreading itself quite thinly across various genres, producing a disparate body of work which was apt for the sociopolitical revolution happening during the 1970s and 1980s; a period whereby the previously strictly imposed notions of gender, sexuality, race and class were being challenged by 
marginalised groups' burning desire for equality. These films, alongside other media texts, began to intersect with the notion of camp as a way to represent queerness that was nonthreatening and comedic. This in part was a way of disarming the fear of the tentative legalisation of homosexuality which had started in 1967 in the UK, which could have otherwise been considered a threat to the traditional heterosexual way of life at the time. However, in the case of EMI, the choice to build films around successful and established camp entertainment and musical icons of the time, such as Danny La Rue and the Village People, was primarily a commercial strategy employed to attract fans in the hope of big box office returns. Regardless of the motivation, these portrayals gradually incorporated camp performance as a mainstay of both British TV and film, to a point where it became normalised, albeit its 'queerness' elided by its placement in the comedy or musical genre. This article posits that this camp performance, although not presented in a serious format, had the ability to work in a political way that managed to change perspectives and attitudes in the 1970s and early 1980s. As the leading British film company throughout this period, EMI's camp releases can be seen as an integral part of the development of the mainstream camp aesthetic in 1970s Britain. Through analysis of Our Miss Fred (1972) and Can't Stop the Music (1980), both produced by EMI and each exemplifying the shift in attitudes of their era, this article will investigate how EMI operated as a conduit for the expression of camp, related not only to the films' institutional identity but also their national identity, analysing how this was instrumental in changing social mores and attitudes. Although both of these films can be identified as only a small selection of a larger queer wave of media texts that flowed in varying degrees across all cultural fields in this era, the centering of the iconic La Rue and the Village People in their respective star vehicles identify the two films as exemplifying a significant queer presence, however camp that presence might be. 


\section{Camp's Many Faces}

The term 'camp' is one that attracts varied definitions and continues to defy any straightforward and clear explanation of what it is and who it belongs to. 'Camp' as a notion; as a concept; as a sensibility is open to change and part of its slippery inability to be clearly defined is its appropriation and use by different groups at different times. Camp has long been the subject of academic discourse and disagreement, with Susan Sontag's comprehensive study of it as apolitical (Sontag suggests that because camp prioritises form over content, objects of camp aesthetic are necessarily crafted without any political motivation; Sontag 1964). However, this theory has been widely discredited (see Butler (1990); Robertson (1996); Halberstam (2005)), and Bruce Labruce's (2012) parody of Sontag's Notes on Camp effectively demonstrates how the growing importance of camp in popular culture has highlighted its inherently political nature. As Labruce argues, 'the whole goddam world is camp...camp is now for the masses. It's a sensibility that has been appropriated by the mainstream, fetishised, commoditised, turned into a commodity fetish, and exploited by a hypercapitalist system’' (Labruce 2012).

LaBruce suggests that by losing its sophistication and 'secret signification' (and of gay sensibility itself being diffused), that any power camp possessed has now been lost. However, as Pamela Robertson (1996) points out in Guilty Pleasures; Feminist Camp from Mae West to Madonna, the close relationship between the use of camp by gay men and women, as groups traditionally oppressed by straight, middle-class, white masculinity, opens up the notion of 'queer' as being a discursive space. Alexander Doty in Making Things Perfectly Queer: Interpreting Mass Culture, identifies queer discursive space as capable of opposing 'the dominant, straight, symbolic order' (Doty 1993: ???) and, unlike Moe Mayer, who identifies 'queer' space as being exclusively gay, Doty regards it as inhabited by gay, straight and any other gender identity, thus allowing for the concept of the 'queering' of 1970s society. Doty 
discusses the notion of all representation being 'queer by nature' (Doty 1993: xiii) and 'adopting reception positions that can be considered "queer" in some way, regardless of a person's declared sexual and gender allegiances' (Doty 1993: xi). He thereby identifies 'queerness' in political terms as one that references 'a network of non-straight ideas' (Doty 1993: xviii) rather than being allied only to sexuality, and similar arguments can be found in McRobbie (1994) and Shugart and Waggoner (2009).

Not all authors have viewed queer discursive space, especially with regards to camp, in such expansive terms. From Andy Medhurst's perspective, camp,

can't be transplanted, because it isn't just any old way of savouring the ironies of gender. It is the way gay men have tried to rationalize [sic], reconcile, ridicule and (in the Jayne County sense) wreck their own specific relationships with masculinity and femininity. It's ours, all ours, just ours and it's time to bring it home. (Medhurst 1997: 291)

Medhurst proudly and justly asserts camp's origins in the gay male community, but also denies the very nature of camp, which is irrepressible, irreverent, rebellious and incapable of being owned, contained or suppressed by anyone. Medhurst identifies that camp is not 'an entity but a relationship - a relationship between queens and their circumstances' (Medhurst, 1997: 276), thus placing camp as historically specific to male drag shows of the 1940s and their refusal to conform. Pessimistically he sees camp as becoming an amusing diversion for 1960s culture, a bit of fun for a postmodern society that sees camp ripped from its queer roots, transforming from a political act to a cultural commodity, where those appropriating it are regarded as 'gatecrashers'. The need to protect camp from outsiders is understandable as, from 
the outset, members of the gay male community were at serious risk if their sexuality was to be revealed. Camp was their way to flout convention and taunt a homophobic society in a relatively safe way. However, as society has evolved and the postmodern impulse sees all cultural aspects up for grabs, where even former gay clubs, which were safe havens for the queer community, have now become the norm for a 'straight' night out, there is an inevitable erosion of the need for secret languages, secret signs and secret meeting places. Postmodernity has seen differences blurred and part of this is the loss of boundaries between genders and sexualities, with camp becoming the domain of the many rather than the few.

As Medhurst claims, camp ‘was weaned on surviving disdain' (1997: 281), and there needs to be an acknowledgement of other marginalised groups, such as women, of being able to use camp in the same way as gay men to challenge and defend against a patriarchal society trying to oppress them. Medhurst's call for a new terminology for other groups to use rather than 'camp', because of its ownership by the subculture of gay men, seems to be a matter of semantics. A separate name for each subculture to use seems almost ludicrously 'camp' in itself, in the sense of being excessive, exaggerated and theatrical. Preceding the term with its relevant adjective (female camp, lesbian camp, straight camp and so on) allows a recognition of camp as originating within the gay male community while acknowledging that camp's ability to 'vigorously undermine and rigorously reinscribe traditional gender roles' (Medhurst 1997: 276) is available as a political act to all oppressed and marginalised groups. As Medhurst acknowledges in a consideration of Judith Butler's Gender Trouble and its impact on both queer and straight culture:

Paradoxically, this theoreticised vindication of camp threatened to destroy its specific subcultural vitality. For if we conclude that all gender is play and 
performance, then camp, which has long held that conclusion as its cherished secret weapon, no longer has any unique contribution to make. This is because traditional camp needed a system of rigidly policed gender roles as a condition of existence; that system both marginalized [sic] those sexual non-conformists who would not or could not fit into it and at the same time provided in its ridiculous rigidity the raw material for the comic revenge through which they made their marginalization [sic] more bearable. (Medhurst 1997: 282-283)

This acknowledgement reveals that the postmodern erosion of gender and sexuality boundaries was and is an unstoppable and irresistible force that rendered camp open and available to all of those who could use it to resist the conformity imposed on them by an unforgiving heterosexual and phallocentric system. Claiming camp as a practice solely belonging to gay men, only denies its nature and its ability to act on behalf of other marginalised sexual non-conformists (effeminate straight men, butch straight women, 'straight' gay men and so on) who seek the freedom to perform their own personal version of gender and sexuality without being ostracised or threatened.

In terms of this performance specifically in the 1970s, a younger generation were seeking to express a different and more radical gender identity that was being enacted and displayed across all forms of media by pop stars and TV and film actors as transformative role models. This therefore allows a consideration of the stars of various and different media as operating in a camp manner in an act of rebellious non-conformity. Although still appearing to be contained by the patriarchal structure and discourse of the industry and still largely controlled by men, camp actually can be identified as a subversive and political force that can act on behalf of marginalised groups. Although EMI executives were not making a deliberate 
attempt to change societal perceptions, by placing La Rue and the Village People as iconic symbols of each era in its films, they still succeeded in impacting on the audience's perceptions of gay culture and gay characters, aided by the stars' camp performance, thus rendering their 'queerness' as acceptable.

\section{EMI Films in the context of 1970s camp}

EMI became the largest film production and distribution company in Britain during the 1970s and 1980s, but the company's commitment to British film-making and British film-makers was often questioned. As Paul Moody notes:

[Bryan] Forbes [was] determined to mark a resurgence of an industry that had been used and then left to wither by its former US investors. Despite this abandonment, mainstream cinema in 1970s Britain was still 'primarily characterised by its relationship to Hollywood', and how EMI navigated this relationship fluctuated throughout the decade. (2018: 17-18)

Part of this navigation was the company's strategic response to reflect and express the mood of the time, which was one of restless impatience with the past and a longing to live in the moment. The playful and irreverent nature of camp therefore resonated with a young, postmodern generation who had never tasted the deprivation of the immediate post-war years and were presented on a daily basis with the new and experimental in terms of food, music, art, fashion, TV and film and were constantly demanding more of the same. Throughout this shifting and unsettling time span EMI Films's original Head of Production, Bryan Forbes, resigned from his role, and Nat Cohen assumed responsibility for the company's output. EMI's then Head of Entertainment (who oversaw the film division), Bernard Delfont, regarded Cohen 
as 'the sort of filmmaker who knew all there was to know about popular demand' (Delfont 1990: 182) having been the man who supplied the public with the Carry On franchise (another very camp and uniquely British series), while in charge of the production company AngloAmalgamated (which had been subsumed by EMI in 1969). Under Cohen's leadership, the newly-christened Anglo-EMI began to cash in on the success of existing popular TV series that could be translated into film, releasing Up Pompei (1971), On the Buses (1971) and Steptoe and Son (1972) in quick succession, with each of these films also swiftly followed by sequels. Their commercial success was due in part to their existing audience base on television, however, their cinema audience is also likely to have comprised a broad section of the younger generation, who would have appreciated the sense of sexual freedom hinted at in these texts through innuendo, double entendre and content that was more risqué than could be featured on television - each of which can also be identified as aspects of camp.

Any attempt to position EMI and its camp films in an historical lineage that proceeds from where Stephen Bourne ended his Brief Encounters: Lesbians and Gays in British Cinema 1930-1971, must acknowledge that neither Our Miss Fred nor Can't Stop the Music can be said to represent the notion of 'glorious honesty' that Bourne identified in several pre-1970s productions (Bourne 1996). Bourne's in-depth and insightful analysis reveals a more subtle or covert queer presence in the 1930s, that requires a thorough interrogation in order to disclose its very existence. However, as queer portrayal becomes more apparent and overt after the Second World War, homophobia and negative representations were triggered as a response to the perception of homosexuality becoming a threat to the established heterosexual order. With the Sexual Offences Act 1967 legalising homosexual practices that were consensual, in private and between two men aged 21 or over, the discomfort and fear this elicited in some aspects of society was reflected in a range of media texts, especially in British cinemas. As Bourne notes 
of Walk a Crooked Mile (1970), 'The message of the film appears to be a warning to gay men in 1970 to watch out, especially those who think they may have found "freedom" after the passing of the 1967 Act.' (Bourne 1996: 224). Although the 1960s and 1970s film scene is peppered with more positive portrayals of queerness that Bourne explores, the acceptance of homosexuality as 'normal' still had a long way to go. Within this context, pre-1970s camp representations are regarded by Bourne as reductive and stereotypical. However, as the film industry advanced into the 1970s it was these camp performances that became more prevalent, ensuring a consistent queer presence in film that was to be instrumental to the future normalisation and acceptance of gay representation.

\section{Queer theory and the camp star persona}

Queer theory is closely related to gender theory and the work of Judith Butler, which considers gender and, consequently, sexuality, as a social construction that supports a patriarchal society. The laying bare of these constructions as the mechanisms that maintain a culture where the white, heterosexual, able-bodied, middle-class male is the dominant ideal, enables those outside that ideal to challenge and subvert representations and identities to work in their favour instead. As Marinucci considers when looking at the relationship between queer and feminist theory:

Within queer theory, what is sometimes described as a rejection of binary contrasts is perhaps better described as social constructionism ... [which] is the belief that such identity categories are historical and cultural developments. This does not necessarily mean that they have no empirical basis, but it does mean that the categories are empirically underdetermined 
... [which] occurs when empirical evidence alone provides an insufficient basis for choosing one paradigm over another. (2010: 34$)$

This consideration, which challenges the notion of binary oppositions of male/female, straight/gay, black/white and so on, allows a relationship to be forged between each of these marginalised groups as being outside the prevailing dominant standard and therefore having to fight for fair and accurate representation in the media. In the case of the gay community and women, camp is particularly beneficial in its ability to undermine and subvert the notion of gender construction and thereby also, sexuality.

In order to comprehend how this subversion operated in 1970s society and how that decade's popular culture became 'queered' through the heterosexual appropriation of camp, the creative products of this era, such as EMI's film releases, provide a useful conduit through which to examine the meanings of camp at work. A study of La Rue and the Village People as iconic camp figures, who influenced and changed perspectives and attitudes through the spectacle of their star personas, will further reveal how and why camp operates in a political manner. As Dyer (1998) argued, film stars are an integral part of the economic structure of the film industry, so that even though their inclusion in a film does not guarantee financial success, 'The economic importance of the stars is of aesthetic consequence in such things as the centring of spectacle on the presentation of the star, and the construction of narratives which display the star's image' (1998: 12). The construction of their star personas through the repetition of their camp performances and the reinforcement of this by the affirmation of the audience, reveals a close relationship between star and viewer that Dyer identifies in this case as 'anomie'. This is defined by Dyer as: 'You feel anomie because you are outside society in general; you feel alienated because you are outside the ruling groups in society' (ibid.: 48). Therefore, audiences 
identify with the star, who may not represent their specific marginalised group, but who represents their position in society. Camp stars can be even more important to marginalised audiences, as at

the heart of camp lies the fundamental sensibility of resistance and revolution. Its excesses and exaggeration continually question and oppose authority and the establishment. In this way it is an ideal weapon for the oppressed repressed that do not have recourse to the usual channels of protest. Therefore, the most extreme form of camp is the most effective. (Bradley 2010: 124)

Anglo/EMI's choice of stars for its films were deliberately calculated to tap into this rebellious camp persona, setting the company apart from the more staid reputation that Forbes's EMI releases had generated thus far. The covert gay audience of the 1970s and 1980s would certainly be drawn to films that promised the camp stylings of these prominent and iconic 'gay' figures, as would their straight counterparts, although more for the entertainment value of the playful and excessive performances this entailed.

\section{Danny La Rue's camp star persona and Our Miss Fred}

Danny La Rue, as a successful star of the stage and TV who appealed to mainstream audiences, was naturally looking to transition into films. As he states in his autobiography From Drags to Riches,

On 22 June 1972, the television version of Danny La Rue at the Palace was screened by Thames TV and went on to top the Jictar tele-ratings for the most-watched ITV 
programme of that week...I had conquered cabaret, pantomime, the West End stage, and now television...only films remained. (1987: 160)

He was 'talked into' doing the film by Lord Ted Willis, who wrote the original story and according to La Rue, he was attracted to the part of Fred Wimbush by being able to play non-drag roles within the film as well as being 'disguised as a woman' for the majority of the time (ibid.: 162). This claim may have been a strategy to remove himself from any suspicions of being gay, but could also have been a tactic to bring his particular brand of mainstream camp to a larger audience, not only to further his career but also to make audiences more aware of the fluid nature of gender and sexuality. As a gay man in the 1970s, he had to hide his sexuality but, as a drag performer, he was able to scathingly critique the society that oppressed him. His well-established success and popularity pinpointed him as a prime candidate to star in his own film vehicle and Anglo/EMI recognised this potential. The film is a romp through what is supposed to be the French countryside (actually Norfolk) near the end of the Second World War, with the Nazis desperately defending the last gasp of occupation by taking all allies prisoner, including British soldiers, in an attempt to ward off their inevitable defeat. The story, written by Ted Willis, who was also responsible for Doctor in The House (1956) and Doctor at Sea (1961) (a series not as saucy as and certainly more respectable than the Carry On franchise), was to perpetuate a similar sense of comedic accidents and misunderstandings. This played on La Rue's ability to pass as a highly attractive and desirable woman, which allows him to fool and defeat the Nazis and rescue a group of 'helpless' schoolgirls, along with their very butch headmistress and rather naive teacher. The premise that his drag queen persona enables him to be a more effective soldier than the rest of his regiment who are easily captured and imprisoned, is camp comedy at its height, exemplifying the playful yet pointed nature of the concept as spoken of by Ronald Bryden as a 'sharp sexual hostility, a repudiation of sexual 
roles... [that] covers itself with protective humour (quoted in Howes 1993: 101). Drag queens or, as La Rue and others were known in the 1960s and 1970s, 'female impersonators', utilise this 'protective humour' to render their verbal critique and gender bending performance seemingly harmless but disturbingly uncomfortable, as they blur boundaries and subvert masculinity. The awareness of the audience of La Rue's performance (or the performance of any drag queen in fact) as a cisgender man impersonating a cisgender woman inevitably raises political questions around gender as a social construction. Although the audience's acceptance of this performance might be read as a reinforcement of the gender binary, there is an argument that as a well-established theatrical form of entertainment, where the drag artist passes as and is accepted as a woman within that environment, that there is also an appreciation of the art and the artifice of the construction. Therefore, the audience receives the dual nature of the drag queen as male/female as part of a performance, where masculinity and femininity are fused and the character of the queen is permitted a freedom to excessively express herself in a way that women or gay men were seldom allowed. This positions the drag queen as a powerful but contradictory figure that contains both genders but is actually neither. Sitting as she does on the boundary between both, her camp performance and use of camp humour builds a bridge between her and the audience that renders this as acceptable and even 'normal'. This effectively presents the drag queen as a figure of resistance and rebellion, a type of Trojan Horse, accepted in but carrying diverse and perverse ideas of change and transformation.

In Our Miss Fred, the camp performance begins with La Rue's character's surname, 'Wimbush', immediately forming associations with female genitalia. We first see La Rue as a 'straight' man in uniform rushing on to the stage to perform as the main attraction. He eventually appears in blonde wig, red dress and full make up as the very epitome of glamour. What we see for the next ten minutes is a full-on drag queen act that foregrounds La Rue's star persona, heavy with innuendo and asides to the audience. As the female love interest in the 
show, Fred brings smut to the stage with sophistication and aplomb in a delightfully camp performance, pronouncing the word 'Count' as 'cunt' when referring to her fiancée and telling the audience 'That's not all that will come between us' when her husband-to-be worries that the class difference between them will obstruct the course of their love. Cue the arrival of the Nazis to cut the performance short, where Fred laments that he is 'dressed as a bird' (a very masculine, 1970s phrase) and that he "came here to murder Germans - and look at me - dressed up as a tart!'. This appears to be an attempt to reassert La Rue's masculinity and reassure the male audience of his heterosexual status, despite his glamorous and sexualised female appearance. As Moody speculates: 'La Rue has to portray himself as a heterosexual [in the film] ... which says a lot about ... early 1970s attitudes to homosexuality even if the main character is known as a drag artist' (2018:108). Drag queens will attest to the fact that their drag personas are separate and complete characters in their own right and Fred as a man adjusts his language to suit his attire, sprinkling his conversations with an abundance of 'mates' and softening his tone and stance as a woman when in a dress. As the film progresses we are introduced to other extremes of both masculine and feminine models, with a randy Frenchman attempting to steal Fred's virtue, to which she responds with an appropriate drag queen riposte, 'You can't put a square peg where there's no square hole!' In this fashion, La Rue's character continues to be developed as quite powerful and 'masculine', despite being dressed as a woman, while also displaying good, honest British bravery, bravado and humour to overcome adversity and the threat of invasion. As Fred's journey continues he/she then encounters a group of 'sexy' schoolgirls and their over-protective headmistress, who is convinced that all men are potential rapists, and their innocent and clueless teacher, who looks up to Fred as a feminist ideal who is glamorous, powerful and assertive. La Rue's drag queen persona is positioned as far more accomplished and attractive than any of the other women we encounter in the film, who, while still lusting after the underage schoolgirls, as any red blooded 1970s 
male would, actually becomes an aspirational model for all of the women in the group. In terms of queer theory, the contradictory figure of Fred, neither male or female but simultaneously both, manages to disrupt the traditional binary model of gender and sexuality, thereby revealing the social construction of male/female and homosexual/heterosexual as 'historical and cultural developments' rather than 'natural' and 'normal' occurrences (Marinucci 2010: 34). In terms of camp performance and spectacle, the most memorable scene from the film is when Fred gate-crashes a fashion show being hosted by the Nazi general who desires the character. In a bizarre moment, we are treated to a dazzling array of La Rue's most glamorous gowns, which is reminiscent of scenes from a 1950s Hollywood musical, such as How to Marry a Millionaire (1953) or Funny Face (1957), where the narrative action is suspended in an instant of sheer fantasy that showcases La Rue's ability to perform as a 'model' woman. In a similar manner to Mulvey's (1975) concept of spectacle being focused on the female body, which is fragmented and displayed for male contemplation and pleasure, the fashion show was usually inserted into these movies in order to attach the glamour of the star performer to the garments on display (and in turn, sell fashion trend to the public). However, with La Rue's gowns, this is about presenting the star as an excessive and camp, but still successful, form of femininity. The tension between La Rue as a man who traditionally drives the narrative and his drag persona as a 'woman' as the site of spectacle who freezes the action, presents La Rue as a camp figure who not only elides the boundaries between genders, but also reveals the concept of gender as an aesthetic artifice that can be constructed from clothes and make up. As Christopher Isherwood explains through his character Charles in The World in the Evening:

You can't camp about something that you don't take seriously. You're not making fun of it: you're making fun out of it. You're expressing what's basically serious to you in terms of fun, artifice and elegance. (1999: 51) 
The exaggeration and excess of La Rue's performance throughout the film, both as a woman and a man, can be identified with this notion of camp as 'fun, artifice and elegance', but when also considered in relation to queer theory and placed in a wider cultural and sociopolitical context, can be seen to express a unique British identity that is closely bound to that of Anglo/EMI as an institution itself. The need to appeal to a transnational as well as a national audience can be seen in the inclusion of such Hollywood elements as the fashion show and well known British stars such as La Rue and Lance Percival (who plays a 'randy, dandy' airman, as an example of straight, camp masculinity), who would be recognised on both sides of the Atlantic. However, the narrative construction with the camp figure of La Rue at its centre and the ribald dialogue built around innuendo and double entendre, is clearly related to the British tradition of the pantomime and the variety shows of the music hall. As cultural forms, both of these types of entertainment were aimed at the lower classes and, when translated into British cinema, were still targeting a similar demographic (hence the crossover of sitcoms from TV to film, which also attracted a similar viewership). However, in the space of just eight years between Our Miss Fred in 1972 and Can't Stop the Music in 1980, there was another cultural shift that was to impact quite negatively on this strategy.

\section{Can't Stop the Music and the camp tradition}

The Village People were at the height of their fame from 1977 till 1979, and it was on the strength of this star persona, which itself was founded on their camp performance and their musical success, that they were chosen to become the central characters in Can't Stop the Music, a semi-autobiographical vehicle intended to cash in on their fan following. The disco scene was still thriving and hugely popular when the group rose to stardom, but as this had originated in the ghettoes of New York, driven by the gay, largely African American 
community, it was under constant challenge from dominant ideological forces that wanted to suppress the threat to the status quo. As Joe Thomas explains:

During disco's post-classic period (1980-1982), its earlier momentum slowed in the face of increasingly violent negative reactions on the part of its foes, who saw disco as shallow, effete, and to a great extent, too queer. Post-classic disco thus went largely undercover and was heard primarily in gay clubs. (Thomas, 2015)

The film itself can be seen to be a victim of this backlash as its excessively camp content and queer aesthetic challenged and undermined not only the white, patriarchal structure of the 1970s socio-political system, but also threatened the traditional hierarchies of the music establishment. Once disco moved out of the underground gay scene and into the mainstream, not only did it lose its edge and its political impetus, it also became a victim of mass-production so that 'soon, disco was lambasted for crass commercialism, cultural effeteness, formulaic nature, predictability, shallowness, anonymity, licentiousness, and, above all, lack of content' (Lin 2008:87). EMI's decision to finance and produce Can't Stop the Music at this point in time failed to pick up on the cultural and industrial turn against disco as it was rejected by mainstream audiences and retreated back into the covert gay scene. It might have also been affected by the rise of the AIDS epidemic, with the first cases being reported in June 1981, where the gay community became not only the victims but also the scapegoats for the spread of the disease. Therefore, although the innovative camp concept of the film would have appeared a safe bet based on the group's international popularity, the quite sudden and unexpected denunciation of disco and, in turn, gay culture, did have an impact on the film's success at the time. Now, almost 40 years later, it has become a camp, cult classic, that 
demonstrates through its longevity how its camp construction can still resonate with an audience, once removed from its cultural and temporal specificity.

The Village People were a manufactured group assembled by French record producer Jacques Morali in 1977. He was highly successful in the disco world, topping the charts with the Ritchie family (who also appear in the film), but wanted to progress further in the field and

create a camp rock ' $n$ ' roll/dance act that would flaunt homosexual stereotypes yet appeal to gays ... Each member of the group was outfitted to cash in on the homosexual "macho" stereotyping; in addition to the American Indian ([Felipe] Rose) there was a cowboy ([Randy] Jones), a policeman ([Victor] Willis), a hard-hat construction worker ([David] Hodo), a biker ([Glenn] Hughes) and a G.I. ([Alex] Briley). (bettyloumusic.com, 2020)

The film followed a quite traditional narrative construction, based on the popular and successful, 'putting on a show' format familiar from classical Hollywood musicals. In effect, this results in a series of musical numbers, loosely held together by the story of the group's formation, with the introduction of the characters and a romance between Sam Simpson (the ex-model, strong, independent woman of the 1980s archetype), played by Valerie Perrine and Ron White (the muscular but sweet lawyer, seemingly based on a Superman/Clark Kent stereotype) played by a pre-transition Kaitlyn Jenner. Although the musical scenes clearly can be identified as camp in nature, overflowing with excess in terms of costume, performance, and setting in a Hollywood style, it swiftly becomes apparent that the narrative scenes are equally camp, retaining elements that EMI had traded in during the 1970s. Although the screenwriters, producers, director and the majority of the cast are American, the film maintains 
a sensibility rooted in camp British humour, with comedy scenes that are reminiscent of the Carry On franchise or Anglo-EMI's Frankie Howerd vehicles. Particular scenes that stand out include Sam and Ron returning to Sam's apartment so that Sam can give Jack, the composer behind the Village People's songs, the news that Steve might be interested in signing the group. What follows is a very camp and very British style of slapstick, where Ron attempts to get food out of the oven as the other two are talking and ends up spilling it all over his trousers. As a narrative device, this effectively debags him in readiness for a later sex scene, but also serves as a camp moment expressed through farcical humour. As Leslie Smith argues, farce refers to

absurd and ridiculous situations, and the farce-writer's ability to make us accept the impossible is possible. The starting point in farce may be normality; but that normality is pushed further towards absurdity, anarchy, even nightmare...Farce...is 'the disciplined expression of anarchy, the logical presentation of a crazy world.' (1989: 12)

In Can't Stop the Music this is nowhere better illustrated than when Sam and Ron decide to run auditions for the remaining members of the group in Ron's respectable and staid law office. Ron's previously established naivety and ignorance of showbusiness renders the premise of the scene believable and therefore possible, and normality is located outside the office doors. But as they open, so the farce begins to unfold and normality is pushed to the limits of absurdity. The excessive camp of showbusiness erupts onto the screen as numerous men in revealing and extravagant costumes perform various theatrical acts, including fire twirling baton jugglers in miniscule gold shorts and a body builder chanting 'Body, body, wanna feel my body, body, wanna touch my body' while he lifts weights, before ripping off his paper thin jumpsuit to reveal tiny briefs and an oiled and muscled torso. Finally, 
'Leatherman' (Hughes) appears in a leather jacket, chaps and hat with a handlebar moustache, leaps on top of the piano and performs Danny Boy to gain a place in the group. This all takes place amidst the chaos of a multitude of performers all vying for a spot in the group, which when placed inside the respectability of a law office, represents anarchy and absurdity. However, somehow the logic of 'putting on a show' negates the impossibility of such a situation occurring and the audience are effectively drawn into the narrative world of the film, where what is to follow takes place within the logic of a showbusiness framework. The relationship of farce with the concept of camp is clear here, particularly if we consider Isherwood's definition of low camp as 'a swishy little boy with peroxided hair, dressed in a picture hat and a feather boa pretending to be Marlene Dietrich' (1999: 51). As we progress through the film the musical performance scenes are presented within a fantasy logic: the construction worker (Hodo) is pursued by seductive women in red; the first group performance takes place in an idealised version of Sam's backyard; an audition performance takes place in the producer's studio; the hit track YMCA is performed at the YMCA; a milk advert features milk marketed in the same manner as champagne; and eventually, the finale features the newlysigned group performing at a benefit organised by Ron's mother. Each scene focuses on the body of the performers, incorporating close ups on hips and groins as they gyrate and thrust, thereby presenting the male body as spectacle and supplying a queer subtext. This is seen most clearly in the YMCA scene, which features a bevy of half-naked men in various physical activities in the gym, including in the shower with excessive amounts of foam, all set to the Village People's biggest and most enduring hit, YMCA (which itself contains heavily suggestive lyrics). Whether it was the film's farcical content, the thinly veiled camp and queer subtext, the poor timing of its release as the fashion for disco was waning, or a combination of all these factors, the film was a critical and financial failure. However, it is understandable why EMI greenlit this production, as the incorporation of camp performance and camp aesthetics 
into its films until then had been a remarkably successful strategy, which had served also as a way of embedding its releases into the cultural and socio-political fabric of the time. For British filmgoers, this tactic

allowed for audiences to feel a cultural connection to a film that was not necessarily set in their country of origin, by dint of recognising elements within it that were identifiably part of a shared cultural heritage. This acknowledgement of the broader international influences on a production does not necessarily diminish the film's national elements; in fact, for some audiences, it reinforces them and enables a broader conception of British cinema based on cultural, rather than purely industrial, terms. (Moody 2018: 206-7)

In Can't Stop the Music, the British audience was able to identify with a narrative construction based in farce, with its elements of camp and camp performance. In the earlier Our Miss Fred, it was the iconic status of La Rue that lent the film its international appeal. In both productions, the campery of the narrative was instrumental in allowing a successful interaction with the text for British and non-British audiences alike.

\section{Conclusion}

Camp as a universal language that is capable of disrupting and subverting the 'natural' and the 'normal', revealing it as artifice and pretext, is not a new concept and, as used by the marginalised groups of gay men and women in the past, provided a useful and effective tool of resistance to the establishment. Once this was incorporated as part of the comedy genre in film and TV, camp entered the mainstream, reaching a wide and diverse audience and gradually 
becoming part of a much larger, postmodern impetus for change. EMI's inclusion of camp in its productions was not a conscious drive to behave in a political manner by normalising homosexuality as acceptable; instead, its inclusion was more about a recognition of camp's nature as a commodity that would sell films. However, the company played a role as an integral part of British culture in the 1970s, which saw a massive shift in gender and sexual politics that was to inevitably change social perceptions and attitudes, albeit slowly. The historical timing of EMI's creation at a point of such radical, political and cultural flux meant that its productions were necessarily inflected with these transitions, occurring primarily in a younger generation hungry for transformation and innovation. Responding to this need, EMI managed to release films that expressed this era of difference, while also embracing the national past and conveying a new institutional identity that was firmly rooted in the culture of the moment. In so doing, EMI adjusted to a rapidly changing industrial environment and cultural landscape by producing texts that interacted with the notion of camp in a playful, farcical manner and, ultimately, helped to alter the representation of queerness on screen for the better.

\section{References}

Bettyloumusic.com, Village People Biography, [Accessed: 08/05/2020]

Available from http://www.bettyloumusic.com/villagepeoplebiography.htm

Bourne, S. (1996), Brief Encounters: Lesbians and Gays in British Cinema, 1930-1971, London: Cassell.

Bradley, P. (2010), 'The politics of camp in 1970s television', in British Culture and Society in the 1970s: The Lost Decade, L. Forster and S. Harper (eds), Newcastle upon Tyne: Cambridge Scholars Publishing, pp. 119-131.

Butler, J. (1990), Gender Trouble. London: Routledge 
Cleto, F. (1999), Camp: Queer Aesthetics and the Performing Subject: A Reader, Edinburgh: Edinburgh University Press.

Doty, A. (1993), Making Things Perfectly Queer: Interpreting Mass Culture, Minneapolis, MN: University of Minnesota Press.

Dyer, R. (1998), Stars, London: BFI.

Dyer, R. (2004), Heavenly Bodies: Film Stars and Society, Abingdon: Routledge.

Halberstam, J. (2005), In a Queer Time and Place: Transgender Bodies, Subcultural Lives New York and London: New York UP

Harper, S. and Smith, J. (2011), British Film Culture in the 1970s: The Boundaries of Pleasure, Edinburgh: Edinburgh University Press.

Howes, K. (1993), Broadcasting It: An Encyclopaedia of Homosexuality on Film, Radio and TV in the UK 1923-1993, London: Cassell.

Isherwood, C. (1999), 'The World in the Evening.' in Camp: Queer Aesthetics and the Performing Subject: A Reader F. Cleto (ed.) Edinburgh: Edinburgh Press, pp. 49-52.

Kirsch, M. (2016), Queer Theory and Social Change, Taylor and Francis: London.

Labruce, B. (2015), Notes on Camp/Anti Camp, brucelabruce.com [Accessed 10/04/2020]

Available from http://brucelabruce.com/2015/07/07/notes-on-camp-anti-camp/

Legislation.gov.uk [Accessed:03/03/2020]

Available from http://www.legislation.gov.uk/ukpga/1968/71/enacted

Mulvey, L. (1999), 'Visual Pleasure and Narrative Cinema', in S. Thornham (ed.) Feminist Film Theory: A Reader, Edinburgh: Edinburgh University Press, pp. 58-70.

McRobbie, A. (1994), Postmodernism and Popular Culture, London: Routledge.

Meyer, M. (1994), The Politics and Poetics of Camp, London: Routledge.

Robertson, P. (1996), Guilty Pleasures; Feminist Camp from Mae West to Madonna, London:

I.B. Taurus. 
Shugart, H.A. \& Waggoner, C. (2009), Making Camp: Rhetorics of Transgression in U.S. Popular Culture, Tuscaloosa, AL: University of Alabama Press.

Sontag, S. (1964), 'Notes on Camp', Partisan Review 31: 4, pp. 515-30

Sontag, S. (1999), 'Notes on Camp' in Camp: Queer Aesthetics and the Performing Subject:

A Reader F. Cleto (ed) Edinburgh: Edinburgh Press, pp. 53-65.

Smith, L. (1989), Modern British Farce: A Selective Study of British Farce from Pinero to the Present Day, Basingstoke: The Macmillan Press Ltd.

Thomas, J. (2015), Disco and Dance Music, glbtq archive [Accessed: 11/05/2020]

available from http://www.glbtqarchive.com/arts/disco_A.pdf 